\title{
An Unusual Cause of Overt Upper GI Bleeding: Retrograde Jejunogastric Intussusception
}

\author{
Hilmi D. Elsiddig ${ }^{1}$, S.H. Suliman' ${ }^{1}$ El.H. Salim Omer ${ }^{1}$, Elnour Mustafa², Mohamed G. Alnedar ${ }^{1}$, \\ Yousif Mohd Khair ${ }^{1}$, S.Z. Ibrahim ${ }^{1}$
}

'Department of Surgery; '2Department of Radiology

Soba University Hospital and University of Khartoum, Sudan

\section{ABSTRACT}

Retrograde jejunogastric intussusception is a well-recognized, rare, but potentially life threatening long-term complication of gastrojejunostomy. Diagnosis of this condition is difficult in most cases. We report on such a patient who presented with overt upper gastrointestinal bleeding. The complication developed thirty years after the primary surgery without history of acute upper abdominal pain in spite of a long segment of gangrenous jejunum inside the stomach. Resection and refashioning of the gastrojujenostomy was performed.

Key words: gastrojejunostomy, retrogradejejunogastric intussusception, bleeding, strangulation

\section{INTRODUCTION}

Retrograde Jejunogastric Intussusception is an uncommon but potentially life threatening complication of gastrojejunostomy or partial gastrectomy. Around 200 cases have been reported in English literature till now (1). This patient presented 30 years after the primary surgery and interestingly he had no epigastric pain in spite of a long segment of gangrenous jejunum inside the stomach. Diagnosis was confirmed by computed tomography.

\section{CASE REPORT}

A 60 years old man presented with three days history bilious vomiting. On admission, he vomited one liter of dark blood. There is no history of upper abdominal pain. He has undergone vagotomy and gastrojejunostomy for peptic ulcer 30 years back and he was asymptomatic until his recent admission to the emergency department. Patient was dehydrated; with pulse rate 110/min and BP $100 / 60 \mathrm{~mm}$ of $\mathrm{Hg}$. He has an upper midline scar. Epigastric region was
Corresponding author: Hilmi Daoud Elsiddig, MD Assistant Professor Department of Surgery University of Khartoum Consultant General Surgeon Soba University Hospital Postal address: P.0 Box 8081 Khartoum Al Amarat, Sudan E-mail: hilmidaoud@gmail.com

Received: 08.06.2016 Accepted: 19.08.2016

Copyright ( $)$ Celsius Publishing House 
distended and there was a vague feeling of epigastric mass. Laboratory investigation showed haemoglobin $10 \mathrm{gm} \%$, White cell count 10,000 /cmm with $87 \%$ polymorph, Plain X-ray abdomen was within normal limit. After initial resuscitation, upper GIT endoscopy was performed which revealed a large clot obscuring the distal stomach. CT abdomen with oral contrast showed small bowel loops in the stomach (fig. 1). Emergency laparotomy was carried out immediately. Stomach was found hugely distended with an intraluminal bowel loops. The presence of posterior gastrojejunostomy was confirmed with intussusception of efferent jejunal loop into the stomach. A gastrostomy was done which revealed intussuscepted gangrenous efferent jejunal loop. Then intussusception was reduced, the gangrenous segment was resected with resection of the oedematous area of gastrojejunostomy. End to end jejunal anastomosis was performed and the big gastrostomy was partially closed (reduced). A new gastrojujenostomy was done in two layers. The patient had an uneventful postoperative course and was discharged on day eight.

\section{DISCUSSION}

Retrograde jejunogastric intussusception was first described by Bozzi in apatient with gastroenterostomy (2). According to the type of intussuscepted loop, JGI is classified into three types: type I, antegrade or afferent loop intussusception; type II, retrograde or efferent loop intussusception; and type III, combined form (3). Efferent loop JGI is seen in $80 \%$ of the cases as in the

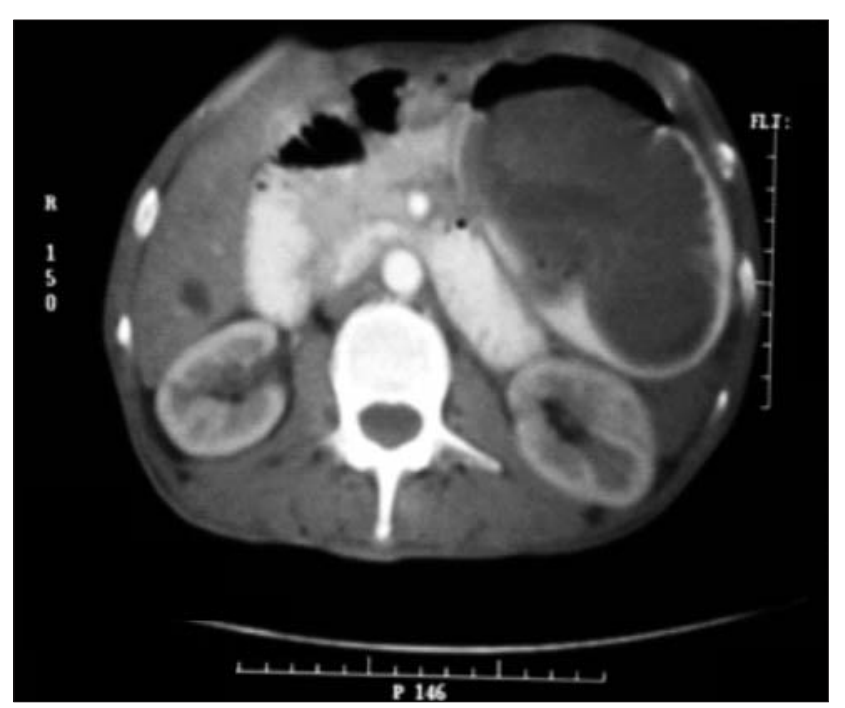

Figure 1 - Emergency CT- Scan of the abdomen: Dilated stomach with intragastric non-homogeneous mass compatible with bowel loops

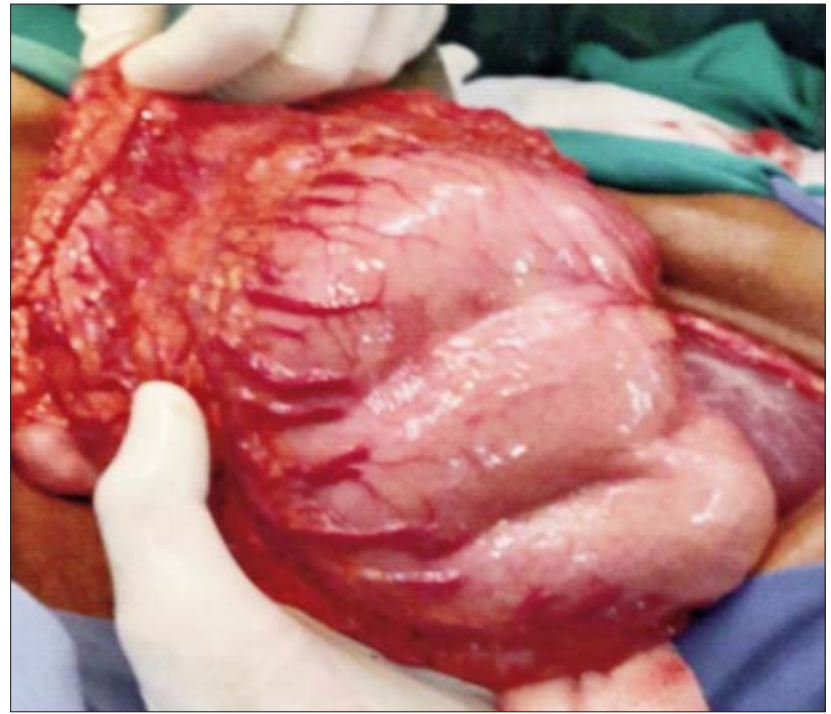

Figure 2 - Intra operative photograph showing small bowel loops inside a dilated stomach

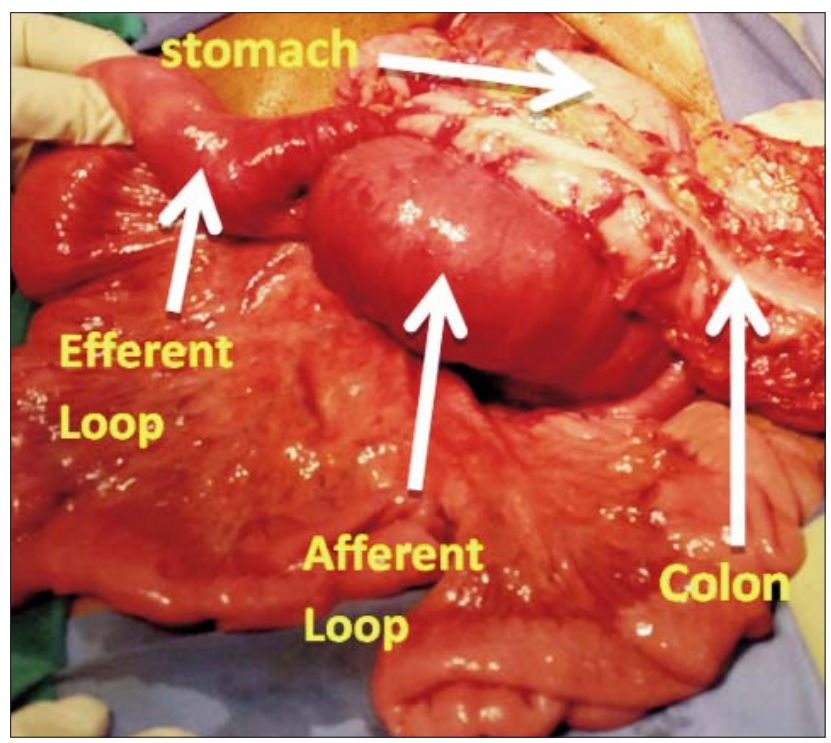

Figure 3 - Intra operative photograph showing a dialted afferent Ioop of a retro colic gastrojujenostomy

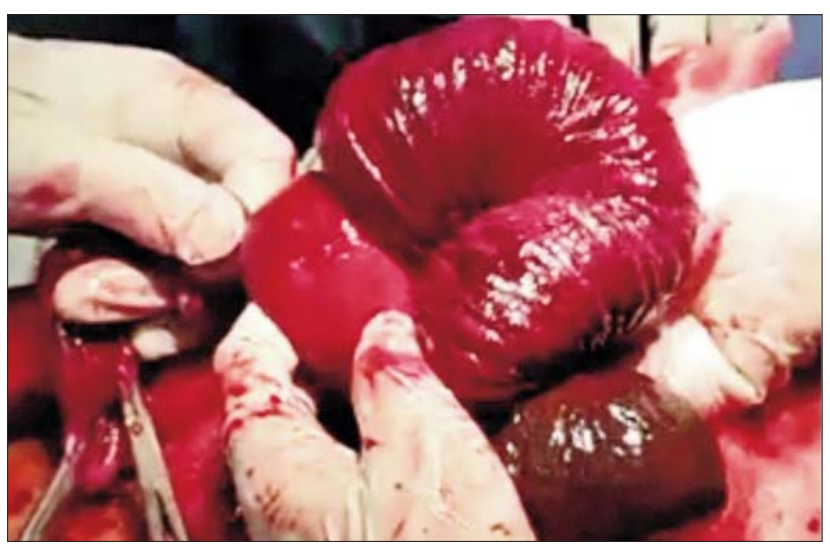

Figure 4 - Intra operative photograph showing gangrenous jejunalsegment after dismantling 
present case. Two different forms of JGI have been described according to its clinical presentation (4). In the acute form, incarceration and strangulation of the intussuscepted loop causing acute severe epigastric pain, vomiting, and subsequently, hematemesis generally occur, however, spontaneous reduction is usual in the chronic type (1). A palpable abdominal mass can be observed in almost half of the cases (5). In most of the case reports, severe epigastric pain is an important early symptom of JGI $(1,6)$ however in this case report there is no history of epigastric pain in spite of a gangrenous jejunum and the reason is not well known.

The treatment for JGI is surgical intervention as soon as possible. Surgical options include reduction, resection $(6,7)$ and revision of the anastomosis, and fixation of the jejunum to adjacent tissue like mesocolon depending on the conditions found during the operation. In this case report, resection and revision of the anastomosis were done.

\section{CONCLUSION}

Retrograde JGI is a very serious life-threatening complication of gastric surgery. There is a wide variation in the lapse time between the gastric surgery and occurrence of JGI, as seen in the present case. When a patient who has had history of gastric operation presents with epigastric pain, vomiting and haematemesis, the possibility of JGI should be considered along with more common diagnoses such as a recurrent stomach ulcer. Because this condition is life-threatening, awareness of this rare complication is essential to save live.

\section{REFERENCES}

1. Kshirsagar AY, Shinde SL, Langade YB, Pujari SG, Jeur AS. Retrograde jejunogastric intussusception with strangulation after posterior gastrojejunostomy. Med J Armed Forces India. 2008 Jul;64(3):282-3. doi: 10.1016/S0377-1237(08)80121-9. Epub $2011 \mathrm{Jul} 21$.

2. Bozzi E. Annotation, Bull.Acad Med. 1914;122:3-4.

3. Shackman R. Jejunogastric intussusception. Brit J Surg.1940;27:47580.

4. Archimandritis AJ, Hatzopoulos N, Hatzinikolaou P, Sougioultzis S, Kourtesas D, Papastratis G, et al. Jejunogastric intussusception presented with hematemesis: a case presentation and review of literature. BMC Gastroenterol. 2001;1:1. Epub 2001 Jan 4.

5. Waits J0, Beart RW Jr, Charboneau JW. Jejunogastric intussusception. Arch Surg. 1980 Dec;115(12):1449-52.

6. Pervin SS, Biswas SK. Retrograde Jejunogastric Intussusception: A Case Report. Faridpur Med. Coll. J. 2010;5(1):32-34

7. Samarasam I, Chandran B, Shanker U, George B, Chacko A, Mathew G. Jejunogastric intussusception: an unusual cause of haematemesis. Can J Gastroenterol. 2005 Dec;19(12):735-6. 